\title{
Adenosine Concentration in Umbilical Cord Blood of Newborn Infants after Vaginal Delivery and Cesarean Section
}

\author{
LARS IRESTEDT, INGRID DAHLIN, TORBJÖRN HERTZBERG, ALF SOLLEVI, AND \\ HUGO LAGERCRANTZ
}

Departments of Anesthesia and Intensive Care and Pediatrics, Karolinska Hospital, Stockholm, Sweden

\begin{abstract}
Umbilical blood was collected immediately at birth $(<30 \mathrm{~s})$ in full-term infants after vaginal deliveries $(n=33)$ and elective cesarean sections $(n=11)$. Blood gases, plasma adenosine, hypoxanthine, and catecholamine concentrations were determined. In vaginally born infants the median arterial adenosine concentration was found to be $0.46 \mu \mathrm{M}$ (range $0.13-2.06$ ) and the venous $0.48 \mu \mathrm{M}$ (0.09-1.62). These levels were significantly higher $(p<$ 0.01 ) than in infants delivered by elective cesarean section; $0.16 \mu \mathrm{M}(0.04-0.42)$ in the artery and $0.17 \mu \mathrm{M}(0.02-$ $0.56)$ in the vein. Vaginally born infants showed about a 4 fold higher level of umbilical arterial catecholamines than infants born by elective cesarean section. There was a strong inverse correlation between arterial hypoxanthine concentration and $\mathrm{pH}(r=-0.81, p<0.01)$. It is suggested that increased adenosine release at vaginal delivery modulates the stress response elicited by the strong catecholamine surge and may furthermore exert protective effects in perinatal asphyxia. (Pediatr Res 26:106-108, 1989)
\end{abstract}

The adenosine metabolite hypoxanthine has been found to be released in high concentrations during perinatal asphyxia and is suggested to be an indicator of the severity of hypoxemia (1-4). During hypoxemia increased hypoxanthine production may also be due to an increased adenine nucleotide degradation in skeletal muscle through the route from inosine monophosphate to inosine (cf. 5). The fetus may, however, sustain short periods of moderate hypoxemia also in normal vaginal delivery during uterine contractions (6). It is at present unclear whether this degree of intermittent physiologic fetal hypoxemia during normal delivery is associated with release of adenosine, hypoxanthine, or other purines. The production and release of adenosine seem also to be closely linked to the balance between substrate supply and demand, and therefore increased formation of adenosine may occur during increased metabolic activity (7).

Adenosine is a potent vasodilator (8) and exerts inhibitory influence on metabolic processes such as lipolysis (9). It also effectively counteracts myocardial stimulatory effects of catecholamines (10). Furthermore, adenosine or its analogues have been demonstrated to depress breathing particularly in the neonate $(11,12)$. Thus, enhanced formation of adenosine during fetal hypoxia could theroretically be involved in a physiologic defense against hypoxia through its action on metabolism, respiration, and hemodynamics.

Received November 14, 1988; accepted April 15, 1989.

Correspondence Lars Irestedt, Department of Anesthesiology and Intensive Care Karolinska Hospital, S-104 01 Stockholm, Sweden.

Supported by the Swedish Medical Research Council ( 5234 to HL and 7485 to AS), Expressen's Prenatal Foundation, Stiftelsen Allmänna BB (to HL), and Swedish Association against Heart and Chest Diseases (to AS).
The present study was undertaken to determine the concentrations of adenosine and the metabolite hypoxanthine in umbilical artery and venous blood during delivery with low (elective cesarean section) or high (vaginal delivery) degree of stress (13), as indicated by the marked difference in plasma catecholamine levels.

\section{MATERIALS AND METHODS}

A total of 44 infants was studied; 33 infants were delivered vaginally and 11 infants by elective cesarean section. All women who delivered vaginally received pethidine $(100 \mathrm{mg}$ intramuscularly and routine pudendal block (lidocaine $1 \%, 10+10 \mathrm{~mL}$ ). Nine cesarean sections were performed under epidural anesthesia (bupivacaine $0.5 \%$ ) and two under general anaesthesia. Only term infants delivered after normal pregnancies and without complications were investigated. Clinical data are presented in Table 1.

Analyses. The umbilical cord was doubly clamped within $10 \mathrm{~s}$ after birth. Blood samples for the determination of adenosine were collected both from the umbilical artery and vein (within $30 \mathrm{~s}$ ) in precooled syringes containing a stop solution to prevent degradation and formation of adenosine $(20 \mu \mathrm{M}$ dipyridamol, $10 \mu \mathrm{M}$ erythro-9-(2-hydroxy-3-nonyl) adenine-hydrochloride, 4 $\mu \mathrm{g}$ indomethacine in $2 \mathrm{~mL}$ saline). The samples were then further cooled and centrifuged in a microfuge $(10000 \times g$ for $1 \mathrm{~min})$. The supernatant was transferred to a tube with 500 pmol N2N2-dimethylguanosine, which was used as an internal standard. The samples were deproteinized with perchloric acid to a final concentration of $0.4 \mathrm{M}$. The precipitate was removed by centrifugation at $10000 \times g$ for $1 \mathrm{~min}$. The supernatant was titrated with ammonium acetate to $\mathrm{pH} 8.8$ and then stored at $-20^{\circ} \mathrm{C}$ until analysis. For further details see Reference 12. An arterial blood sample was also taken for analyses of $\mathrm{pH}$ and $\mathrm{PCO}_{2}$, hypoxanthine, and plasma catecholamines. Adenosine was analyzed with HPLC, using UV detection as described elsewhere (9, 14). The detection limit of adenosine and hypoxanthine in plasma samples was 30 and $100 \mathrm{nM}$, respectively. The coefficient of variation for the sample preparation and analyses of adenosine is less than $10 \%$ and for hypoxanthine less than $5 \%$. Plasma catecholamines were also determined with HPLC with electrochemical detection (15). The sensitivity of that method was $0.1-$ $0.2 \mathrm{nM}(15)$.

Statistics. Data are presented as mean $\pm \mathrm{SD}$, and statistical analyses were performed with the Wilcoxon rank test (for unpaired data) and with regression analyses according to Spearman rank test.

\section{RESULTS}

Infants delivered vaginally had similar Apgar scores and $\mathrm{pH}$ as infants delivered by cesarean section, but significantly higher 
Table 1. Birth wt (BW), Apgar scores at 1 and $5 \mathrm{~min}$, umbilical artery $\mathrm{pH}$ and umbilical artery concentration of noradrenaline (NA) and adrenaline $(A)$ after vaginal delivery (VD) and elective cesarean section (CS)

\begin{tabular}{|c|c|c|c|c|c|c|}
\hline Group & $\begin{array}{c}\text { BW }(g) \\
\text { Mean } \\
(\mathrm{SD})\end{array}$ & $\begin{array}{l}\text { Apgar } 1 \\
\text { Mean } \\
(\mathrm{SD})\end{array}$ & $\begin{array}{c}\text { Apgar } 5 \\
\text { Mean } \\
\text { (SD) }\end{array}$ & $\begin{array}{c}\mathrm{pH} \\
\text { Mean } \\
(\mathrm{SD})\end{array}$ & $\begin{array}{c}\text { NA }(\mu \mathrm{mol} / \mathrm{L}) \\
\text { Median } \\
\text { (Range) } \\
\end{array}$ & $\begin{array}{c}\mathrm{A}(\mu \mathrm{mol} / \mathrm{L}) \\
\text { Median } \\
\text { (Range) }\end{array}$ \\
\hline $\mathrm{VD}(n=33)$ & $\begin{array}{l}3527 \\
(553)\end{array}$ & $\begin{array}{c}8.8 \\
(0.8)\end{array}$ & $\begin{array}{c}9.6 \\
(0.5)\end{array}$ & $\begin{array}{c}7.25 \\
(0.06)\end{array}$ & $\begin{array}{c}34.2 \\
(5.3-373.9)\end{array}$ & $\begin{array}{c}4.2 \\
(0.1-18.0)\end{array}$ \\
\hline $\mathrm{CS}(n=11)$ & $\begin{array}{l}3233 \\
(171)\end{array}$ & $\begin{array}{c}8.6 \\
(0.7)\end{array}$ & $\begin{array}{c}9.8 \\
(0.4)\end{array}$ & $\begin{array}{c}7.30 \\
(0.05)\end{array}$ & $\begin{array}{c}8.8 \\
(2.3-89.7)\end{array}$ & $\begin{array}{c}1.3 \\
(0.4-7.4)\end{array}$ \\
\hline
\end{tabular}

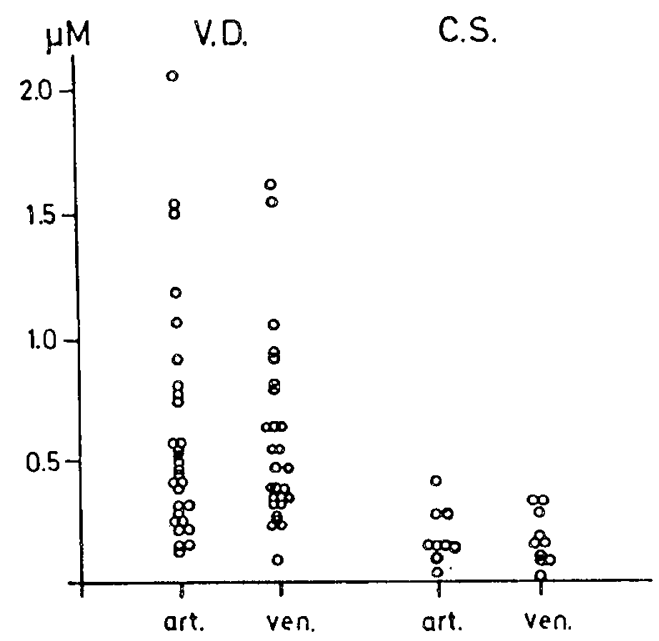

Fig. 1. Individual umbilical arterial and venous adenosine concentrations in newborn infants after vaginal deliveries $(V D)$ and elective cesarean sections $(C S)$.

noradrenaline $(p<0.01)$ and adrenaline $(p<0.01)$ concentrations (Table 1). The median concentration of plasma adenosine was found to be $0.46 \mu \mathrm{M}$ (range $0.13-2.06$ ) in umbilical arterial blood and $0.48 \mu \mathrm{M}(0.09-1.62)$ in venous blood after vaginal deliveries (Fig. 1). There was no significant difference in the arterial and venous adenosine concentrations. The plasma adenosine concentrations after cesarean section were significantly lower than during vaginal delivery; in the umbilical arterial blood $0.16 \mu \mathrm{M}(0.04-0.42, n=9)$ and in the venous blood $0.17 \mu \mathrm{M}$ $(0.02-0.56, n=10)(p<0.01)$.

The median umbilical arterial hypoxanthine concentration was $3.77 \mu \mathrm{M}(0.39-10.62)$ and the venous concentration 2.97 $\mu \mathrm{M}(0.31-6.87)$ in vaginal deliveries and the corresponding values for cesarean section delivered infants was $0.56(0.23-2.78)$ and $0.43(0.16-1.62) \mu \mathrm{M}$. The arterial hypoxanthine concentration in vaginal deliveries was significantly $(p<0.01)$ higher than the venous concentration, but there was no significant arteriovenous difference in the cesarean section group. There were no linear correlations between the arterial adenosine concentration and arterial $\mathrm{pH}$, base deficit, $\mathrm{PCO}_{2}$, or noradrenaline concentrations in the vaginal deliveries, but the adrenaline concentration was found to be inversely correlated with the adenosine concentration (Table 2). However, there were significant correlations between umbilical arterial hypoxanthine versus arterial $\mathrm{pH}$ (Fig. 2), $\mathrm{PCO}_{2}$, and $\mathrm{BD}$, but not versus noradrenaline and adrenaline (Table 2).

\section{DISCUSSION}

Higher levels of adenosine and hypoxanthine were found in infants born after normal vaginal delivery than in infants delivered by elective cesarean section. The latter had plasma adenosine concentrations in a similar range as resting adults (14). It is
Table 2. Correlation matrix for umbilical arterial adenosine and hypoxanthine concentrations versus base deficit $(B D), \mathrm{PCO}_{2}$, $p H$, and noradrenaline $(N A)$ and adrenaline $(A)$

\begin{tabular}{lllllc}
\hline & \multicolumn{5}{c}{ Correlation matrix } \\
\cline { 2 - 6 } & $\mathrm{BD}$ & $\mathrm{PCO}_{2}$ & $\mathrm{pH}$ & $\mathrm{NA}$ & $\mathrm{A}$ \\
\hline Adenosine & 0.14 & 0.35 & -0.33 & -0.12 & $-0.37^{*}$ \\
Hypoxanthine & $0.66 \dagger$ & $0.58 \dagger$ & $-0.81 \dagger$ & -0.26 & 0.05 \\
\hline
\end{tabular}

$* p<0.05$.

$\dagger p<0.01$

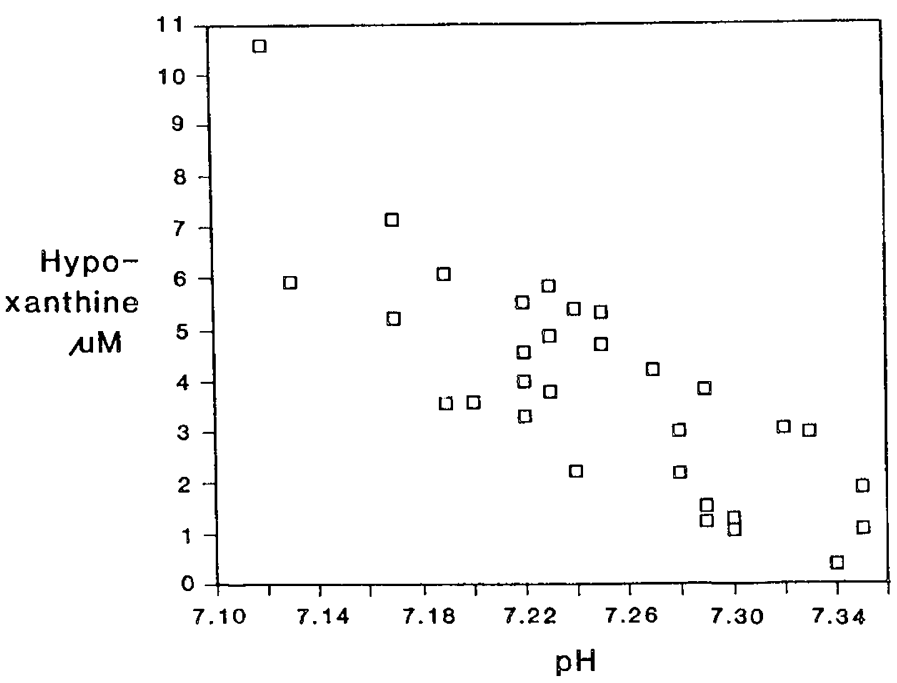

Fig. 2. Correlation of hypoxanthine concentrations with $\mathrm{pH}$ in umbilical arterial blood from vaginally born infants $(r=-0.81 ; p<0.01)$.

difficult to determine local production of adenosine from increased plasma concentration due to the extremely short halflife of adenosine in blood or plasma $(<10 \mathrm{~s})(5,7)$. The rapid elimination of adenosine in blood is due to uptake into endothelial cells and other tissue elements, as well as to enzymatic degradation to inosine. These elimination processes are inhibited by the described method of sampling which offers a fairly reliable quantitation of adenosine at the site of sampling in human blood (14). Elevated blood adenosine concentrations can, therefore, only indicate an enhanced adenosine production which could lead to much greater tissue levels of adenosine during hypoxia than what can be judged from the corresponding plasma levels. Despite the rapid blood elimination, our study indeed demonstrated increased umbilical cord levels of adenosine in vaginally born infants.

It is not possible to judge whether the elevated adenosine levels are due to an increased release of adenosine from the fetus or from the placenta, because there was no significant umbilical arteriovenous difference (4). Plasma adenosine concentrations increased quickly during hypoxia in fetal lambs (16). Adenosine was also found to accumulate rapidly during ischemia in the rat brain (17) and in ischemic myocardium (18). Intermittent tissue 
hypoxia may, therefore, be involved in the increased adenosine levels seen in the vaginally delivered infants in our study. Although there were no signs of clinical asphyxia in these babies, it is well known that fetal $\mathrm{PO}_{2}$ may drop to $0-2 \mathrm{kPa}$ during uterine contractions (6), which in turn may be sufficient to elicit increased release of adenosine from the tissues. Furthermore, increased metabolism due to the catecholamine surge might also contribute to enhanced fetal adenosine production. However, adenosine release has also been demonstrated from human hypoxic placental cells in vitro (19). It therefore seems possible that both the fetus and the placenta may contribute to the elevated umbilical adenosine concentration. The lack of uterine contractions during elective cesarean section and the lower catecholamine level is compatible with the present finding of low adenosine levels in these babies.

The umbilical artery levels of hypoxanthine correlated inversely with the corresponding $\mathrm{pH}$ values. This linear correlation was much stronger than previously demonstrated $(1,2)$, and was seen in the absence of clinical asphyxia. This strong correlation is in contrast to previous results where no correlation was seen even during asphyxia (4). Our correlation indicates an imbalance between supply and demand for oxygen in the vaginally delivered infant. The fact that these infants had higher arterial levels of both adenosine and hypoxanthine in comparison to the infants born by caesarean section, and to adults, suggests that hypoxanthine emanates from adenosine. However, it is also possible that some hypoxanthine is formed via breakdown of inosine monophosphate in fetal skeletal muscle during hypoxia.

From the present findings of elevated plasma levels of adenosine after vaginal delivery it is possible to speculate about a physiologic modulatory effect by adenosine on the fetal intrapartal adaptation.

Adenosine may have a protective effect during periods of hypoxia by its metabolic inhibitory effect (9) and by its ability to locally increase tissue blood flow, thereby increasing oxygen and substrate delivery (20). It may also modulate the circulatory and metabolic effects caused by the strong sympathoadrenal activation $(13,22)$, which occur during vaginal delivery. This is supported by our previous findings of surprisingly small hemodynamic differences in vaginally delivered infants, when compared to infants born after cesarean section, despite the markedly divergent sympatoadrenal stimulation in these two modes of delivery (21). Further, vaginally delivered infants seem to be under the influence of a strong inhibitory effect of lipolysis at birth (22), which could reflect a modulation of catecholaminestimulated lipolysis by increased fetal adenosine levels. Finally, typical symptoms of birth asphyxia, i.e. terminal apnea, muscle hypotonia, and hypothermia $(12,23)$, may partially be caused by the increased adenosine concentrations. All these effects would tend to decrease overall oxygen requirement and would thus serve as a protective mechanism in a condition with a limited oxygen supply.

\section{REFERENCES}

1. Saugstad O 1975 Hypoxanthine as a measurement of hypoxia. Pediatr Res 9:158-161

2. Thiringer K 1982 Hypoxanthine as a measure of foetal asphyxia. Sheep experiments and a clinical study in human neonates. Gradual Thesis, Göteborg, Sweden

3. O'Connor MC, Harkness RA, Simmonds RJ, Hytten FE 1981 Raised hypoxanthine, xanthine and uridine concentrations in meconium stained amniotic fluid and during labour. Br J Obstet Gynaecol 88:375-380

4. O'Connor MC, Harkness RA, Simmonds RJ, Hytten FE 1981 The measurement of hypoxanthine, xanthine, inosine and uridine in umbilical cord blood and fetal scalp blood samples as a measure of fetal hypoxia. $\mathrm{Br} \mathrm{J}$ Obstet Gynaecol 88:381-390

5. Sollevi A 1986 Cardiovascular effects of adenosine in man; possible clinical implications. Progr Neurobiol 27:319-349

6. Saling E 1966 Das Kind im Bereich der Geburtshilfe. G. Thieme Verlag, Stuttgart

7. Berne RM 1986 Adenosine: an important physiological regulator. News Physiol Sci 1:163-167

8. Arch JRS, Newsholme EA 1987 The control of the metabolism and the hormonal role of adenosine. In: (eds) Campbell PW, Aldridge WN (eds) Essays in Biochemistry, vol 14. Academic Press, London, pp 88-123

9. Sollevi A, Fredholm BB 1981 The antilipolytic effect of endogenous and exogenous adenosine in the canine subcutaneous adipose tissue in situ. Acta Physiol Scand 113:53-60

10. Schrader JR, Baumann G, Gerlach E 1977 Adenosine as inhibitor of myocardial effects of catecholamines. Pflugers Arch 372:29-35

11. Hedner T, Hedner J, Wessberg P, Jonason J 1982 Regulation of breathing in the rat: indication for a role of central adenosine mechanisms. Neurosci Lett 33:147-151

12. Lagercrantz H, Yamamoto BB, Fredholm NR, von Euler C 1984 Adenosine analogues depress ventilation in rabbit neonates. Theophylline stimulation of respiration via adenosine receptors? Pediatr Res 18:387-390

13. Irestedt L, Lagercrantz H, Hjemdahl P, Hägnevik K, Belfrage P 1982 Fetal and maternal plasma catecholamine levels at elective cesarean section under general or epidural anesthesia versus vaginal delivery. Am J Obstet Gynecol 142:1004-1010

14. Sollevi A, Östergren J, Fagrell B, Hjemdahl P 1984 Theophylline antagonizes cardiovascular responses to dipyridamole in man without affecting increases in plasma adenosine. Acta Physiol Scand 121:165-171

15. Hjemdahl P, Daleskog M, Kahan T 1979 Determination of plasma catecholamines by high performance liquid chromatography with electrochemical detection: comparison with a radioenzymatic method. Life Sci 25:13.

16. Mentzer RM, Ely SW, Lasley RD, Mainwaring RD, Wright EM, Bome RM 1985 Hormonal role of adenosine in maintianing patency of the ductus arteriosus in fetal lambs. Ann Surg 202:223-230

17. Winn HR, Rubio R, Berne RM 1981 Brain adenosine concentration during hypoxia in rats. Am J Physiol 241:H235-242

18. Berne RM 1963 Cardiac nucleotides in hypoxia: possible role in regulation of coronary blood flow. Am J Physiol 204:317-322

19. Petraglia F, Lim AT, Vale W 1987 Adenosine 3,5-monophosphate, prostaglandins, and epinephrine stimulate the secretion of immunoreactive gonadotropin-releasing hormone from cultured human placental cells. J Clin Endocrinol Metab 65:1020-1025

20. Berne RM 1980 The role of adenosine in the regulation of coronary blood flow. Circ Res 47:807-813

21. Faxelius G, Hägnevik K, Lagercrantz H, Lundell B, Irestedt L 1983 Catecholamine surge and lung function after delivery. Arch Dis Child 58:262-266

22. Hägnevik K, Faxelius G, Irestedt L, Lagercrantz H, Lundell B, Persson B 1984 Catecholamine surge and metabolic adaptation in the newborn after vaginal delivery and caesarean section. Acta Paediatr Scand 73:602-609

23. Mehta AK, Kulkarni SK 1983 Effect of purinergic substances on rectal temperature in mice: involvement of P1-purinoceptor. Arch Int Pharmacodyn Ther 264:180-186 